\title{
A Quantitative Correlational Study on Diversity Management, Career Planning, and Career Advancement for Women
}

\author{
Lisa R. Brown \\ Walden University \\ Teresa Lao \\ Walden University \\ Sharon Michael-Chadwell \\ Capella University
}

Gender disparity is a pervasive problem in the United States automotive industry particularly in critical decision-making positions where male employees dominate the field. Three significant issues were addressed in this study: Diversity management, career planning, and women's career advancement. The quantitative correlational study investigated how diversity management and career planning are related to women's advancement in the US automotive industry to improve the representation of women in management and senior-level positions. The gender gap in management was examined through the organizational justice theory and grounded by the glass ceiling metaphor. Ninety-two full-time employees from an automotive company in Atlanta participated through Survey Monkey. Perceived Facilitators to Career Advancement Scales, the Perceived Barriers to Career Advancement Scales, and the Job Descriptive Index Scales were analyzed using multiple regression. The research questions addressed the individual and combined relationship between diversity management and career planning to career advancement.

Keywords: glass ceiling, gender disparity, career advancement, diversity, career planning

\section{INTRODUCTION}

Women in the United States has contributed to the increase in workforce for the past 60 years. The Bureau of Labor Statistics (BLS, 2018a) reported there were almost 75 million women in the labor force in 2017, equaling almost 47\% of the total United States workforce. Labor force is defined by BLS (2018a) as those employed or those who are actively seeking employment. Data from the United States Department of Education (DOE) (2016) indicated that women who enter the workforce are highly educated with more than half of all bachelor's (57.2\%) and master's degrees (59.2\%) in 2015. For 2019, a reported 29.5 million women held a bachelor's degree, which ties with existing number of men, 29.3 million, who held a college degree (Pew Research Center, 2021).

Although women have advanced academically, they still continue to face challenges in the workplace, particularly for middle management and executive level positions in male-dominated fields (Catalyst, 
2014). Women face struggles in advancing to decision-making positions because of the presence of gender bias, which is defined as "differential evaluations and treatment of women relative to men" (Begeny, et al., 2020, para. 3). Many may think this is not happening because it is something that they have not experienced themselves. Leaders need to be more cognizant in recognizing that bias exists even if this is something that is not reported often by women.

In male-dominated fields that includes construction, transportation, technology, and utility industries, only $25 \%$ of women make-up that workforce there (Catalyst, 2017b). Women are not choosing to work in these fields because it is a career that has not been a popular choice for them, or their degree programs do not lend to a career that are traditionally popular to men. If more women are working in these maledominated industries, then they could probably make their presence more and be considered for these management positions. This statement or belief was reported by Begeny, et al., (2020) who indicated that by increasing the presence of women in male-dominated professions, gender bias and the issue of inequality will eventually be reduced. It may be incorrect to believe that if more women join a certain profession in droves, then the organization will suddenly embrace an inclusive culture.

Beaman, Duflo, Pande, and Topalova (2012) reported that many factors affect gender diversity and low representation in male-dominated fields such as perceived self-efficacy, occupation choice, compensation, and representation in decision-making positions (Beaman et al., 2012). The gender gap in these fields suggests that implementing a gender diversity initiative through the employment pipelines could further the growth of women in leadership positions. The purpose of this quantitative correlational study was to investigate how diversity management and career planning are related to the advancement of women in the United States automotive industry to improve the representation of women in management and senior-level positions. The sample frame was 92 female employees of one automotive firm in the United States. The criteria for the participants include the following: they must work full-time, are salaried employees who have a four-year college degree, and a minimum of two years of experience working in one automotive company.

\section{BACKGROUND}

The influx of women into the United States workforce over the past 70 years contributed to a gradual social movement where women moved from caregiver roles in the home to economic contributors in society (Budgeon, 2014; Catalyst, 2017a). Social and political movements including the feminist movement, equal opportunity legislation, academic achievement, career aspirations, and shifts in family responsibilities led to the feminization of the workforce (Budgeon, 2014). Women's participation in the labor force has fluctuated over time, peaking in 1999 at 60\% (BLS, 2018a; Catalyst, 2017a). There were approximately 75 million women employed in the United States labor force in 2017 (Bureau of Labor Statistics [BLS], 2018b). Unfortunately, women are still underrepresented in decision-making positions despite their big presence in the workforce (McKinsey \& Company, 2015). The limited number of women in decisionmaking positions may negatively affect the number of women available to enter decision-making positions such as managers, directors, vice presidents and higher (Catalyst, 2017a; McKinsey \& Company, 2016).

In an earlier study, Prieto et al. (2009) questioned the effect that the management of diversity has on an organization's bottom line. A review of literature by Prieto et al. the various forms of diversity could be associated with improvements in (a) strategic decision-making, (b) innovation, and (c) organizational performance. Patrick and Kumar (2012) noted that while diversity management does have a positive effect in the workplace, qualified women might feel a sense of affirmative action stigmatization in the positions they hold. Ellemers (2014) suggested there are barriers that are inherently invisible that could be based on the culture of the organization or expectations that tend to favor men than women.

Underrepresentation of women in the workforce may discourage other women from seeking employment in male-dominated fields. Thus, if there are women who are just entering the workforce, they may not gain the competitive advantage over male counterparts if they do not have other women to serve as mentors to guide them towards career advancement. According to Toossi (2015), the few women who take part in decision-making processes are often in the position to serve as mentors and sponsors to other 
women in the pipeline. These women have a lot to contribute in terms of developing and guiding other others to be in the decision-making positions they are currently in.

Even though there is an increase in the number of women in decision-making positions, evidence suggested that an increase of female participation in the workforce did not significantly impact female

representation at the board level (Alliance for Board Diversity, 2016; Catalyst, 2018). This lack of representation may signify that gender diversity is not currently in place or a significant issue for many organizations. For example, the representation of women on Fortune 500 boards peaked in 2016 at 1,100 (20\%) of over 22,000 board members (Alliance for Board Diversity, 2016; Catalyst, 2018). Toossi (2015) suggested organizations implement programs and initiatives to expand the gender profile of their boards and executive teams. Studies showed evidence to suggest that diversity management (DM) and career planning $(\mathrm{CP})$ positively influence the pipeline of women into decision-making positions and ultimately position women for board membership (Alliance for Board Diversity, 2016; Catalyst, 2017a, Catalyst, 2018, McKinsey \& Company, 2016). The implementation of these programs could result in a significant increase in the number of women in middle management and senior leadership positions (Toossi, 2015).

Gender diversity initiatives vary by organization based on the type of programs and policies implemented and factors such as company size, available resources, and organizational culture. For example, a small corporation in a female-dominated industry workforce is likely to have different program needs than a small corporation in a male-dominated industry. The male-dominated firm may have recruitment and mentoring programs designed to attract, hire, retain, and promote women. Women who engaged in DM initiatives adapted to an organization's culture by participating in mentoring and networking. Women who actively participated in DM are likely to advance in the pipeline (Ellemers, 2014; Olson, Parsons, Martins, \& Ivanaj, 2015). CP which consists of (a) career management, (b) development assignments, and (c) geographic mobility were reported to be what women need if they are to advance into management and senior leadership (Cook \& Glass, 2014; French \& Strachan, 2013). Unfortunately, the variances in DM and CP programs and initiatives outcomes suggests a need for more research to examine how DM and CP are related to the advancement of women (Williams, Kilanski, \& Muller, 2014).

\section{Workplace Inequality}

Women have made great strides in getting a college degree, in addition to completing trainings and qualification to make them marketable in the labor market. However, women continue to face invisible and artificial barriers to career advancement than their male counterparts; these barriers are more evident as women advanced into C-suite-level management positions (Devillard, et al., 2014).

Deloitte (2015b) attributed the lack of women in leadership positions to limited access to social networks, few key leaders as role models, flexible work practices, and lack of sponsorship. The number of barriers increase as women advance in their careers (Sabharwal, 2015). Female leaders and executives often encounter situations where they have been set up for failure, pushing them over the glass cliff.

While federal statutes have been enacted to eradicate gender inequality in the workplace, these laws have not eliminated glass ceiling barriers (Budgeon, 2014). The presence of the glass ceiling in the workplace can be prevented by encouraging individuals to have a conversation about this topic. Some employees may not see the glass ceiling as a big issue because it is something they have not experienced but encouraging open-dialogue or training initiated by management or HR could make the organizational culture more open to feedback when the glass ceiling is experienced by women. In male-dominated industries, the barriers that women face are real, but these challenges can be resolved by getting everyone invested in combating these challenges from happening.

Organizational leaders must recognize the presence of gender disparity in the workplace by having policies and procedures that would prevent any type of bias from occurring. In the hiring process, for example, Reiners (2021) talked about the implementation of a blind screening process so that gender identification is not easily recognized among applicants. With blind screenings, the name, race, interests, activities, etc. are not provided so there is no way for hiring managers to assume a person's identity.

Leadership also needs to support DM and CP initiatives to be able to support career advancement of women (Devillard et al., 2014). There are women, though, who have overcome the glass ceiling barriers 
despite the gender gap. Sabharwal (2015) stated that women are less likely to succumb to glass ceiling barriers and the glass cliff when they perceive and experience fairness in the workplace. Diversity Management and $\mathrm{CP}$ are tools that could alleviate barriers to the career mobility of women.

\section{Women in Male-Dominated Industries}

The underrepresentation of women in male-dominated industries could be the reason why there is an unconscious bias to advance men over women (Appelbaum, Shapiro, Didus, Luongo, \& Paz, 2013; Catalyst, 2017a; Clevenger \& Singh, 2013). Unconscious bias towards men contributes to the gender advancement gap at the managerial and senior level (Watkins \& Smith, 2014). Unconscious gender bias is described as constructs and mental models that are based on beliefs about gender that are influenced by standards, values, traditions, and experiences. Watkins and Smith (2014) stated the career trajectory of women who work in male-dominated industries is often hindered by programs and practices that are unconsciously biased towards men and reflect stereotypically masculine criteria.

Watkins and Smith (2014) stated the underrepresentation of women at the senior level contributed to a workplace culture that promoted male biases and led to subjective gender standardization in talent management systems that value masculinity. Talent management systems in male-dominated industries fail to adequately support the career advancement of women (Catalyst, 2017a). Male-dominated industries tend to have a culture where talent management policies and practices are influenced by masculine stereotypes for acceptable behaviors and norms. For example, developmental and promotional opportunities often excluded women because of masculine stereotypes and pro-male biases (Watkins \& Smith, 2014). Consequently, the gender imbalance at the executive and senior-levels resulted in less female mobility in male-dominated industries and business sectors (Appelbaum et al., 2013; Walker \& Bopp, 2011). The gender diversity profile of the automotive industry may be a result of an androcentric (male centered) talent management system, which centers on the development of male interests. Programs and initiatives are created intentionally or unintentionally from a male point of view.

\section{PROBLEM}

The general topic of this study was women's perceptions of fairness in procedures and the distribution of resources to alleviate artificial and invisible barriers to advancement. For some organizations, the implementation of policies and practices, like diversity management (DM) and career planning (CP), creates opportunities for women to thrive in the workplace (O'Neil, Hopkins, \& Sullivan, 2011; Spurk, Kauffeld, Barthauer, \& Heinemann, 2015). There was a need to investigate how DM and CP are related to the career advancement as a blueprint for filling the talent pipeline with highly skilled women in the automotive sector (O’Neil et al., 2011; Spurk et al., 2015).

A more diverse workforce can affect organizational performance. Kim and Starks (2016) noted gender diversity at the board level could increase firm value. Women make unique contributions to decisionmaking processes by offering functional expertise, which is sometimes missing when boards lack gender diversity (Kim \& Starks, 2016). Similarly, Reinert, et al. (2016) found a positive correlation between (a) corporate return on investment and (b) gender-diverse management. Badal and Harter (2014) also found a relationship between gender diversity and positive organizational performance at the business-unit level. Not all work fields, however, are gender-diverse, which may specifically be affecting the organizational performance of male-dominated industries.

The scarcity of women in managerial and leadership roles in the United States automotive industry further increases the likelihood women will continue to face barriers to advancement (Deloitte, 2015). The problem that is evident in the workplace is the androcentric system within the United States automotive industry creates an environment that undermines initiatives designed to mitigate barriers that hinder the upward mobility of women into managerial and leadership positions (O'Neil \& Hopkins, 2015; Sabharwal, 2013). The relationship between DM (independent/predictor variable) and CP how(independent/predictor variable) and how they relate to career advancement (dependent/criterion variable) of women in the US automotive industry is still unknown. 


\section{PURPOSE}

The purpose of this quantitative correlational study was to investigate how DM and CP are related to the advancement of women in the United States automotive industry to improve the representation of women in management and senior-level positions. The variable of interest was gender because research indicates women encounter barriers to career advancement and entering leadership in male-dominated industries (Catalyst, 2015; Deloitte, 2015). The research design was correlational, which allowed for the examination of what predictive relationships, if any, existed among the independent and dependent variables (Curtis, Comisky, \& Dempsey, 2016).

An increase in women employed in managerial and leadership roles could contribute to women's career advancement in male-dominated industries such as the automotive industry (Deloitte, 2015; Martin \& Barnard, 2013). The research questions were designed to address the purpose of the study. Multiple regression analysis was used to examine the correlation amongst the DM perceived facilitators scales, CP perceived barriers scales, and career advancement JDI scale for women in the United States automotive industry. Data collection was conducted using SPSS software and results were password-protected.

The questions below addressed the general and specific problems identified in the problem statement. There were 10 questions. The general question was followed by nine specific questions that addressed DM and CP relationships to career advancement. The DM variables were (a) informal networks, (b) mentoring, and (c) cultural fit. Career planning variables are (a) career management, (b) developmental assignments, (c) difficulty getting developmental assignments, (d) career management processes, (e) relationship development, and (f) geographic mobility.

The general research question was: What is the relationship between the linear combination of DM and $\mathrm{CP}$ to the advancement of women working in the androcentric system within the United States automotive industry?

$\boldsymbol{H}_{0 .}$ The linear combination of DM and CP is not related to the level of the career advancement of women working in the androcentric system within the automotive industry.

$\boldsymbol{H}_{a .}$ The linear combination of DM and CP is related to the level of career advancement of women working in the androcentric system within the automotive industry

Specific Research Question 1: What is the relationship between informal networks and the career advancement of women in the automotive industry?

H1. There is no relationship between informal networks and the career advancement of women in the automotive industry.

H1 $\boldsymbol{1}_{\text {. }}$ There is a significant relationship between informal networks and the career advancement of women in the automotive industry.

Specific Research Question 2: What is the relationship between mentoring and the career advancement of women in the automotive industry?

$\boldsymbol{H} 2_{0}$. There is no relationship between mentoring and the career advancement of women in the automotive industry.

$\boldsymbol{H} \mathbf{2}_{a .}$ There is a significant relationship between mentoring and the career advancement of women in the automotive industry.

Specific Research Question 3: What is the relationship between cultural fit and the career advancement of women in the automotive industry? 
$\boldsymbol{H 3}_{0}$. There is no relationship between cultural fit and the career advancement of women in the automotive industry.

$\boldsymbol{H 3}_{\text {a. }}$ There is a significant relationship between cultural fit and the career advancement of women in the automotive industry.

Specific Research Question 4: What is the relationship between problems developing relationships and the career advancement of women in the automotive industry?

$\mathrm{H4}_{0}$. There is no relationship between problems developing relationships and the career advancement of women in the automotive industry.

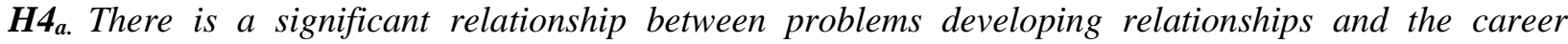
advancement of women in the automotive industry.

Specific Research Question 5: What is the relationship between problems managing one's own career and the career advancement of women in the automotive industry?

H5. There is no relationship between problems managing one's own career and the career advancement of women in the automotive industry.

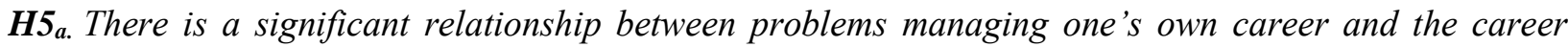
advancement of women in the automotive industry.

Specific Research Question 6: What is the relationship between problems obtaining developmental assignments and the career advancement of women in the automotive industry?

H6. There is no relationship between problems obtaining developmental assignments and the career advancement of women in the automotive industry.

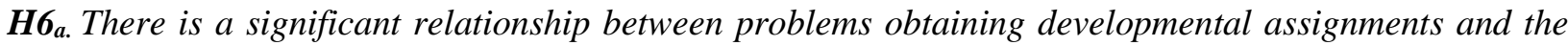
career advancement of women in the automotive industry.

Specific Research Question 7: What is the relationship between problem getting developmental assignments and the career advancement of women in the automotive industry?

$\boldsymbol{H 7}_{\text {. }}$. There is no relationship between problem getting developmental assignments and the career advancement of women in the automotive industry.

$\boldsymbol{H} 7_{a .}$.There is a significant relationship between problem getting developmental assignments and the career advancement of women in the automotive industry.

Specific Research Question 8: What is the relationship between problems with organizational career management processes and the career advancement of women in the automotive industry?

$H_{8}$. There is no relationship between problems with organizational career management processes and the career advancement of women in the automotive industry.

$\boldsymbol{H}_{a}$. There is a significant relationship between problems with organizational career management processes and the career advancement of women in the automotive industry.

148 Journal of Business Diversity Vol. 21(2) 2021 
Specific Research Question 9: What is the relationship between difficulty getting geographic mobility and the career advancement of women in the automotive industry?

H90. There is no relationship between problem difficulty getting geographic mobility and the career advancement of women in the automotive industry.

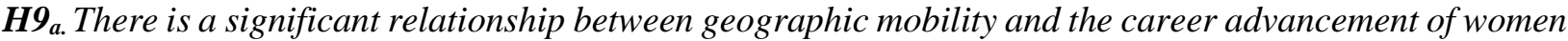
in the automotive industry.

Conducting this study may provide insights to automotive industry leaders to develop programs to increase the number of women in the talent pipeline for leadership positions. Women who are in positions of power may also see the need to contribute to the advancement of women who are new in the field.

\section{Theoretical Foundation}

Greenberg's (1990) organizational justice theory provided the theoretical framework for the study. A derivative of equity theory, organizational justice theory is a multidimensional construct allowing for the measurement of an employee's perceptions of workplace fairness (Fujimoto, Härtel, \& Azmat, 2013). Fujimoto et al. (2013) described fairness in the workplace using three subjective acuities: (a) distributive justice, (b) procedural justice, and (c) interactional justice. Organizations perceived as having great organizational justice tend to have engaged employees who are content with their ability to advance. Moreover, the employees in organizations with greater organizational justice believed the resources are distributed reasonably and equitably (Brown, Lent, Telander, \& Tramayne, 2011; Germain et al., 2012; Hancock \& Hums, 2015; Johnson, 2012; Shaw, Park, \& Kim, 2013). Healthy employer-employee relationships build trust and loyalty, and trust and loyalty contribute to increased job satisfaction and corporate social responsibility. For this study, the predictive relations between DM and CP for career advancement were quantified using the three classifications of Greenberg's (1990) organizational justice theory.

Researchers have used organizational justice theory to investigate barriers to advancement in the workplace (Bukhari \& Sharma, 2014; Downes, Hemmasi, \& Eshghi, 2014; Powell \& Butterfield, 2015). The career advancement of women who are working in professional, managerial, and senior-level positions in the United States automotive industry were examined through a post-positivist lens using organizational justice theory (Greenberg, 1987, 1990) as the theoretical framework. Examining the results using organizational justice theory offered a framework to explain the relationship of DM and $\mathrm{CP}$, and their impact on the career advancement of women (Brown et al., 2011).

\section{SIGNIFICANCE TO THE STUDY}

The business case for increasing diversity in the workforce is inconsistent. There is evidence of the paradoxical effects of diversity in the workplace in studies where diversity influences positive and negative outcomes (Credit Suisse, 2012; Fujimoto et al., 2013; Garnero, Kampelmann, \& Rycx, 2014; Shore et al., 2009). For example, diversity policies may increase engagement and job satisfaction with one group, but disengagement and job dissatisfaction may increase in another group. A review of the literature indicated there is a gap in what is known about how DM and CP are related to the advancement of women in the United States automotive industry. This study is significant because it may add balance to the inconsistent empirical evidence about the viability of a holistic gendered strategy for alleviating visible and invisible glass ceiling barriers in the workplace.

Organizational leaders are experiencing pressure to increase their firms' gender diversity profiles and succession pipelines (Credit Suisse, 2012). Credit Suisse (2012) researchers reported that some organizations with gender diverse boards have gained a competitive advantage. McKinsey and Company (2013) asserted that firms with gender diversity at the board level also had greater gender diversity in middle management positions and better organizational performance than those organizations with homogenous 
boards. Kellerman and Rhode (2017) stressed that women executives and board members can serve as role models, mentors, and sponsors for women who aspire to attain higher-level positions. They presented evidence that suggested firms that have women as board members and in the C-Suite tend to have more women in managerial and the senior level roles (Kellerman \& Rhode, 2017). Furthermore, gender diversity at the senior level and in non-traditional roles like engineering and IT could embolden women in college or those transitioning into new careers to contemplate a career in the automobile sector. Additionally, other male-orientated professions may benefit from the inclusion of women at all levels, such as manufacturing, legal, information technology, and research and design professions.

Interest in understanding gender issues in the automotive industry is high. Several organizations have dedicated resources to understand the glass ceiling phenomenon in the automotive industry (Catalyst, 2014; Deloitte, 2015; inForum, 2012). Organizations such as AutomotiveNext, Southern Automotive Women's Forum, Women in Automotive, and the National Association of Minority Automotive Dealers hold annual conferences where gender issues are a focus. These conferences are ideal venues for presenting the results of this study. This study can be used as a blueprint for how companies could better provide their employees with equal access to resources and opportunities alleged to affect the career trajectory of women toward managerial and leadership positions.

\section{Significance to the Management Field}

Increasingly, governmental and interest groups pressure organizational leaders to improve their gender diversity profiles by infusing their succession pipeline with women. This pressure creates opportunities for women to develop leadership skills and competencies as they ascend into positions of increasing authority (Credit Suisse, 2010; McKinsey \& Company, 2012, 2013). Credit Suisse (2010) researchers suggested organizations with gender diverse boards gain competitive advantage. Furthermore, McKinsey and Company (2013) asserted that firms with gender diversity at the board level had greater organizational performance than homogenous boards.

Additionally, the presence of successful senior-level female role models holding C-suite and board positions in the industry could embolden other women to contemplate careers in all aspects of the automobile sector. The results of this study are significant to the field of management because they help fill the knowledge gap in the literature about gender in the workplace. Also, insights from this study can aid human resource leaders as they work to implement talent management policies for the recruitment and promotion of women into management and senior-level positions.

\section{Significance to Women in Male-Dominated Industries}

Unfortunately, gender incongruences in corporate America exist. Researchers agree that leadership stereotypes and societal attitudes about behaviors and qualities of effective leaders, among other things, contribute to glass ceiling barriers for women (Cook \& Glass, 2014; Koenig, Eagly, Mitchell, \& Ristikari, 2011). Moreover, qualities commonly attributed to a specific gender and certain leadership styles contribute to the barriers that women encounter in attaining leadership roles.

Koenig et al. (2011) described the disparity between what people consider effective leadership qualities and the predominant communal qualities associated with women. Koenig et al. confirmed through a metaanalysis of various paradigms (e.g., think manager-think male, agency-communion, and the masculinityfemininity) that stereotypical beliefs about women's roles and capabilities produce biased evaluations of women as leaders (Koenig et al., 2011). Role incongruity results in gender discrimination at the senior and board levels, which is why it is unsurprising that many leaders who demonstrate agentic qualities (e.g., confident, competitive) are male. The confirmation of cultural stereotypes about leadership, and the cultural preference for women to embrace communal gender roles, present quandaries for women who aspire to positions of power and authority (Koenig et al., 2011).

\section{Significance to Women in the Automotive Industry}

The automotive industry is competitive and requires organizations to incorporate diversity initiatives into their business strategies (Basar, 2015). Each business unit within an organization must understand how 
a diverse workforce contributes to competitive advantage. Understanding the overall impact of women as internal and external stakeholders positively affects organizational performance, thus bolstering the business case for a diversity strategy and active $\mathrm{CP}$ for women. A greater understanding of these principles provides insight into the business imperative for fairness in the workplace. The eradication of extreme pay gaps, inflexible work schedules, poor work culture, insufficient professional networks, and short developmental assignments may increase the number of women at senior and executive levels. Eradicating these barriers can potentially increase the number of women interested in the automotive industry and the overall female talent pipeline.

Empirical research on the perception of DM and $\mathrm{CP}$, and their relationships to career advancement for women in the automotive industry could be more robust. A study of the predictive relationship of DM, CP, and career advancement using organizational justice theory as the framework could expand the existing body of scholarly literature. The results could make a meaningful contribution to the current research on DM practices and organizational justice perceptions that affect the development of female talent in the automotive industry. Basar (2015) stressed that women should actively engage in navigating glass ceiling barriers to advance to positions of authority. This study is significant as I provided greater insight into the correlation between DM and CP, and their impact on career advancement. Researchers may be encouraged by the results and be compelled to conduct additional empirical research on how gendered DM and CP relate to the career advancement of women in non-traditional careers and industries.

\section{Women in the Automotive Industry}

The automotive sector's gender diversity profile suggests a bias towards men. In 2014, the BLS (2014) indicated approximately 1,400,000 women were employed in motor vehicle-related manufacturing, which was just $27 \%$ of all motor vehicle-related manufacturing employees. If automotive industry organizations became more gender-balanced, there might be more women in senior leadership positions and the pipeline (Appelbaum et al., 2013; Badal \& Harter, 2014; Kim \& Starks, 2016; Reinert et al., 2016). Devillard et al. (2014) wrote that closing the gender gap requires senior leadership engagement. Industry leaders must believe in a gender-balanced workforce, which can occur through DM and CP programs (Devillard et al., 2014). The notion that women in leadership is good for the bottom line is the business case (Singal, 2014). Researchers posited the presence of women in leadership positions positively affects organizational financial performance (Hoobler, Masterson, Nkomo, \& Michel, 2018).

Although researchers have focused on specific factors of DM (Credit Suisse, 2012; D'Netto, Shen, Chelliah, \& Monga, 2014) as part of gender-diversity and corporate performance, few have investigated how DM and CP are related to the advancement of women in the United States automotive industry. Few studies exist about the advancement of women working in professional, managerial, and executive positions in the automotive sector, which suggests a gap in knowledge of how DM and CP are related to the advancement of women in the United States automotive industry. This study, thus, was designed to investigate how DM and CP are related to the advancement of women in the United States automotive industry. The results provide insight into the advantages of DM and CP as strategies for career advancement of women. Organizational leaders can use the results of this study to develop effective DM and CP initiatives to increase the number of women in the talent pipeline for leadership positions.

\section{Research Methodology and Design}

The methodology for this study was quantitative even though there was an abundance of qualitative research relating to female advancement in male-dominated industries (Navarro-Astor, Roman-Onsalo \& Infante-Perea, 2017; Wright, 2016); however, what was lacking in past research was empirical data focused on how DM and CP are related to the advancement of women in the United States automotive industry (Hancock \& Hums, 2015; Kretschmer \& Kretschmer, 2013; A. Martin, 2015; Worrall, 2012; Worrall, Harris, Stewart, Thomas, \& McDermott, 2010). The research questions in this study are designed to investigate the relationship amongst DM, CP, and career advancement.

Researchers often examine the relationships among variables in the social sciences (Purdam, 2016). A correlational design allows researchers to examine relationships between variables in a population or 
between similar variables in different populations in non-experimental settings without treatment or outside influence by the researcher (Curtis et al., 2016). Curtis et al. (2016) noted that researchers use correlational designs to (a) determine frequencies and relationships among variables and (b) to infer outcomes based on the data. A correlational design was appropriate for this study because the aim was to identify what, if any, predictive relationships existed between the independent and dependent variables. A correlational design allowed for investigation of the predictive relationships of DM (i.e., independent/predictor variable) and CP (i.e., independent/predictor variable), and their relationships to the women's career advancement (i.e., dependent/outcome variable) in the United States automotive industry. The correlational design was an appropriate design for this study to increase understanding of the degree to which interventional human resources policies and procedures affect the career trajectory of women.

\section{Participant Selection Logic}

Female employees who worked at one US automotive manufacturing organization participated in the study. The firm's human resources department reported there were 638 full-time female employees in professional, managerial, and senior-level positions in facilities across the continental United States. The population criteria ensured participants worked in roles that funneled into the succession pipeline. The inclusion criteria were (a) women; (b) full-time, salaried employees; (c) tenured for at least 2 years, and (d) in professional, managerial, and senior-level positions. Regular, full-time employees work a full schedule, which is typically 40 hours each week (Bartoll, Cortes, \& Artazcoz, 2014).

The population criteria ensured participants experienced the organization's culture and met the minimum criteria for career advancement into management positions. The participant inclusion criteria included (a) college-educated women, (b) in salaried positions, and (c) employed in professional positions or higher. Specifically, participants were full-time employees with at least a bachelor's degree. Professional and management positions included those in Grade 6 or higher, and participants had to have two years of employment with the organization. Excluded were those who (a) were male, (b) had worked at the company for less than two years, (c) lacked a four-year college degree, (d) worked part-time, and (e) were in positions below Grade 6. Furthermore, participants could not be (a) hourly, (c) Foreign Service employees, (d) contractors, or (e) interns. The women in this study were candidates for promotion into managerial and leadership positions.

The organization categorized jobs by grades. Jobs in Grades 6-9 are professional positions. These positions are critical to the succession pipeline, and the employees in these positions are analysts, senior analysts, specialist consultants, and senior consultants. Grades 10-11 are expert managerial positions. Individuals in these positions have direct reports or possess a specific expertise. Grades 12-16 are senior level positions such as directors, senior directors, vice-presidents, senior vice-presidents, executive vicepresidents, and senior executive vice-presidents.

The grade categories were changed to help maintain the anonymity of the participants and the organization. Professional positions were categorized as Group 1, which are Grades 6-9 positions. These positions are critical to the succession pipeline. These positions are analysts, senior analysts, specialist consultants, and senior consultants. Managerial and senior-level positions were categorized as Group 2. Group 2 consisted of positions in Grades 10-16. These positions have decision-making authority. These positions are managers, directors, senior directors, vice-presidents, senior vice-presidents, executive vicepresidents, and senior executive vice-presidents. Senior leaders consider professionals and managers ranked as high performer/high potential in their succession planning discussions.

Participants responded to questions related to (a) gender, (b) ethnicity, (c) age, (d) tenure, (e) education level, and (f) the number of years of industry experience. Table 1 represents the demographic data collected. A total of 96 female employees (specifically, candidates for promotion into managerial and leadership positions) participated in the study. The data of four respondents were classified as outliers after analyzing the data for univariate outliers; therefore, the final sample size was $N=92$. 
TABLE 1

FACTORS AND DESCRIPTIONS

\begin{tabular}{ll}
\hline Factors & Descriptions \\
\hline Demographic Factors & Hierarchical Position \\
& Educational Level \\
& Industry Experience \\
& Tenure \\
\hline
\end{tabular}

Note: Demographic factors will be gathered to investigate whether these factors influence the relationship amongst the variables.

\section{Instrumentation}

The Perceived Barriers to Career Advancement Scales (Lyness \& Thomas, 2000a) allowed me to investigate how the dependent variables were related to the advancement of women in the United States automotive industry. Lyness and Thomas (2000a) developed this instrument to measure the 26 factors perceived as barriers to career advancement on a scale ranging from $1=$ no problem at all, to $5=a$ very serious problem (Lyness \& Thomas, 2000a). The Perceived Barriers to Career Advancement Scales contain six scales: (a) lack of cultural fit, (b) excluded from formal informal networks, (c) lack of mentoring, (d) poor organizational career management processes, (e) difficulty getting developmental assignments, and (f) difficulty obtaining opportunities for geographic mobility. The scales of the instrument appropriately measure DM and CP factors. I did not need permission to use this instrument for educational research (Lyness \& Thomas, 2000a). The use of these scale for education research is permitted without expressed permission (Lyness \& Thompson, 2000a).

The Perceived Facilitators to Career Advancement Scales examine perceived barriers and facilitators of career advancement, career histories, and self-reported career development experiences (Lyness \& Thompson, 2000b). Lyness and Thompson (2000b) created the Perceived Facilitators to Career Advancement Scales to measure participant perceptions of opportunities for upward mobility using a fivepoint Likert-type scale with anchors ranging from $1=$ not a facilitator, to $5=$ a very important facilitator. The Perceived Facilitators to Career Advancement Scales instrument was appropriate for the study because the scales measured employees' perceptions of facilitators for career advancement.

Lyness and Thompson (2000b) posited that there is a correlation among perceptions of career advancement, CP initiatives, and diversity programs (i.e., mentoring, networking, and cultural fit). Table 2 contains the independent variables and the exact scale measurements that were adapted from the Perceived Facilitators to Career Advancement Scales and Perceived Barriers to Career Advancement Scales. The alignment of the variables and scale measurements tested the hypotheses. The use of these scale for education research is permitted without expressed permission (Lyness \& Thompson, 2000b).

\section{TABLE 2}

\section{PERCEIVED FACILITATORS AND BARRIERS TO CAREER ADVANCEMENT SCALES}

\begin{tabular}{ll}
\hline Variables & Scale Measurements \\
\hline Diversity Management & Informal Networks, Mentoring, and Lack of Cultural Fit \\
Career Planning & Managing Own Career, Developing Assignments, Career \\
& Management Processes, and Geographic Mobility \\
\hline
\end{tabular}

Note: Diversity management and career planning will measure the perceived facilitators to career advancement. The demographic factors include the adjacent descriptors. 


\section{Diversity Management}

Diversity management is a human resource practice to increase or maintain variances in human capital while ensuring the variance in human capital does not hinder organizational performance. Diversity management also consists of HR programs to perpetuate heterogeneity in the workplace and reap the benefits of labor force diversity (Spurk et al., 2105). The Perceived Facilitator to Career Advancement Scales were used to measure DM. Participants were to rate the extent to which each of the factors had facilitated career advancement within the organization on a 5-point Likert scale ranging from $1=$ not $a$ facilitator, to $5=$ a very important facilitator:

Informal Networks:

1. Social events and informal interactions with colleagues, either on or off the job

2. Access to informal networks

Mentoring:

3. Moral support and encouragement from your mentor or manager during stressful times

4. Help from your mentor in establishing key relationships

5. Advice from your mentor about how to solve difficult business problems

6. Having senior manager(s) who facilitate(s) your career progress

7. Having role models

8. Having a mentor or someone who provides good advice on career opportunities

9. Working for manager(s) who take an interest in your career

10. Information about organizational politics from your mentor or manager

Lack of Culture Fit:

11. Fitting in or adapting to the culture

12. Having a role model

13. Not being an outsider

14. Not feeling comfortable asserting your views because of possible consequences

15. Feeling that you can't make mistakes and learn from them without threatening your job or your future

16. Feeling like you are held to a higher standard than others

17. People tend to recommend and select people like themselves

\section{Career Planning}

Career planning is a coordinated effort between an employee and manager. In career planning, individuals set career-related goals by assessing (a) current situations, goals, and competencies; and (b) the necessary knowledge and skill development for upward mobility (Spurk et al., 2015). The Perceived Barriers to Career Advancement Scales measure CP. Participants rated the extent to which each of the factors had been a problem to career advancement within the organization using the 5-point Likert scale ranging from $1=$ no problem at all, to $5=$ a very serious problem:

Developing Relationships:

1. Developing relationships with senior managers

2. Developing an informal network

3. Credibility with your peers

4. Being assertive

Managing Own Career:

5. Initiating own job changes

6. Initiating moves across functions and businesses

7. Having a clear idea of your own career goals

8. Taking personal risks

Developmental Assignments:

9. Being offered key job assignments

10. Breadth of assignments or experiences 
11. Having job assignments with bottom line responsibility

12. Early, significant responsibility and accountability for important tasks

Difficulty Getting Developmental Assignments:

13. Not getting the right jobs early in your career (that you need for later advancement)

14. Lack of opportunities to move across functions or businesses

15. Difficulty getting access to critical developmental assignments (e.g., serving on highly visible task forces or committees)

16. Not being considered when promotions for bigger jobs arise

17. Difficulty getting access to opportunities

18. Difficulty getting access to job assignments with bottom line responsibility

19. Not being offered stretch assignments

Poor Organizational Career Management Processes:

20. Poor career development and planning processes

21. Not knowing what the criteria are for advancement

22. Being unsure about how to initiate a job change

Difficulty Obtaining Opportunities for Geographic Mobility:

23. Needing to gain international experience in order to advance

24. Not being considered for jobs that require relocation (domestic)

25. Difficulty getting international assignments

\section{Career Advancement}

Career Advancement, the dependent variable, was measured using the Job Descriptive Index scale (JDI) 2009 version. The JDI scale initially developed by Smith, Kendall, and Hulin (1969) to measure job-related satisfaction examines five aspects of job satisfaction. This instrument has 72 items and measures satisfaction with promotional chances, pay, coworkers, supervision, and work in general. Although the JDI scale consists of five measurements, participants only responded to the statements related to the opportunities for promotion measure.

Career advancement was synonymous with opportunities for promotions. This specific measure contains six scales: (a) good opportunity for promotions, (b) opportunities somewhat limited, (c) promotion on ability, (d) dead-end job, (e) good chance for promotion, (f) very limited, (g) infrequent promotions, (h) regular promotions, and (i) fairly good chance for promotion.

TABLE 3

JOB DESCRIPTIVE INDEX SCALE

\begin{tabular}{ll}
\hline Factor & Scale Measurements \\
\hline Career Advancement & Opportunities for promotion \\
& Opportunities somewhat limited \\
& Promotion on ability \\
& Dead-end job \\
& Good chance for promotion \\
& Very limited \\
& Infrequent promotions, \\
& Regular promotions \\
& Fairly good chance for promotions \\
\hline
\end{tabular}

Note: The Job Descriptive Index Scale measures opportunity for promotion.

Career advancement occurs when an individual possesses higher valued human capital, high performance, and perceived worth to an organization. It is an upward career progression accomplished through successive positions over a length of time (Harris, Pattie, \& McMahan, 2015). The JDI scale 
consists of a checklist of adjectives or phrases that are answered as followed: "Y" agree, "N" disagree, and "?" cannot decide. Participants rated the following phrases:

1. Opportunities for Promotion

2. Opportunities somewhat limited

3. Promotion on ability

4. Dead-end job

5. Good chance for promotion

6. Very Limited

7. Infrequent Promotions

8. Regular Promotions

9. Fairly Good Chance for Promotions

\section{Data Analysis Plan}

Participants responded to a set of questions regarding their demographic background and how DM and CP initiatives related to career advancement. SPSS was used to perform a multiple regression analysis, which was used to analyze the linear relationship of the independent and dependent variables to measure the strength, significance, and the direction of the correlation between the variables. Static Solutions (2013) stated to investigate the research questions, a multiple linear regression should be performed to assess if $\mathrm{DM}$ and $\mathrm{CP}$ are related to career advancement. A multiple linear regression measures the correlation among a set interval/ratio variable on an interval/ratio criterion variable (Statistic Solutions, 2013). In this instance, the independent variables included DM and CP, and the dependent variable was career advancement. The following regression equation (main effects model) was used: $y=b 1 * x 1+b 2 * x 2$; where $Y=$ estimated dependent variable, $c=$ constant (which contains the error term), $b=$ regression coefficients and $x=$ the respective independent variables (Statistic Solutions, 2013).

The multiple linear regression, stepwise regression, was used. This standard method input all independent variables (predictors) concurrently into the model. Variables were evaluated by what they contributed to the outcome of the dependent variable which was dissimilar from the probability provided by the other predictors in the model (Statistic Solutions, 2013). The $F$ test was used to measure whether the set of independent variables jointly predicted the dependent variable. $R$-squared, the multiple correlation coefficient of determination, was stated and used to forecast how much variance in the dependent variable was explained by the set of independent variables (Statistic Solutions, 2013). The $t$ test was used to determine the significance of each independent variable, and beta coefficients were used to determine the degree of prediction for each independent variable. For significant predictors, for each unit increase in the predictor, the dependent variable will increase or decline by the number of unstandardized beta coefficients (Statistic Solutions, 2013).

The assumptions of multiple regression, (a) linearity, (b) homoscedasticity, and (c) multicollinearity, were measured. Linearity assumes a straight-line association between the independent variables and the dependent variable, and homoscedasticity assumes that scores are normally distributed around the regression line (Statistic Solutions, 2013). Linearity and homoscedasticity were measured by using a scatter plot. The nonexistence of multicollinearity suggested that independent variables were not significantly associated and were measured using variance inflation factors. Variance inflation factor values above 10 suggest there is multicollinearity (Statistic Solutions, 2013).

\section{Data Collection}

A total of 165 female employees (specifically, candidates for promotion into managerial and leadership positions) of one United States-based automotive firm participated in the study. Based on the statistical parameters of (a) statistical power $=0.95$, (b) effect size $=0.15$ (medium), and (c) alpha level $=0.05$ (twotailed test), which signifies a 95\% confidence interval and measures the level of error allowed in the data and the tolerable risk of receiving incorrect data projected, the ideal sample size was $N=108$.

The survey was open for 62 days with 165 employees attempting the survey. Only 96 participants answered all the questions, which is required to test the hypotheses. Of the 96 participants, four respondents 
were classified as outliers after analyzing the data for univariate outliers; therefore, the final sample size was $N=92$. Spearman rank correlation coefficient and Pearson correlation were used to analyze the data. The Spearman's correlation determined the strength and direction of the monotonic relationship between the variables. It worked by calculating a Pearson's correlation coefficient on the ranked values of the data. The Pearson correlation determined the direction and strength of the linear relationship between the variables (Thirumalai, Chandhini, \& Vaishnavi, 2017).

To answer the general research question, The Prediction of Opportunities Based on Scale Scores table displays the multiple regression prediction model for opportunities for promotion based on the nine scale scores. To answer each specific research question, The Pearson and Spearman Correlations for Scale Scores with Opportunities for Promotion table displays the Pearson and Spearman correlations for each of the nine scale scores with opportunities for promotion. As for the additional findings, the Pearson and Spearman Correlations for Selected Demographics with Opportunities for Promotion table and the Pearson and Spearman Correlations for Selected Variables with Opportunities for Promotion table displays the Pearson and Spearman correlations for the selected items with the opportunities for promotion. Last, as an exploratory analysis, the Prediction of Opportunities Based on Selected Variables table and Stepwise Regression table displays the results of the stepwise multiple regression model predicting the opportunities for promotion scale based on 55 candidate variables is detailed.

\section{Descriptive Statistics}

Table 4 displays the frequency counts for selected variables. Years with the firm ranged from 2 to 4 years $(31.5 \%)$ to 20 to 25 years $(7.7 \%)$ with a mean of $M=8.53$ years. Years worked in the automotive industry ranged from 2 to 4 years $(17.4 \%)$ to 20 to 34 years $(22.8 \%)$ with a mean of $M=11.91$ years. All were full-time salaried employees, with a majority holding bachelor's degrees $(60.9 \%)$ and the rest having graduate degrees (39.1\%). Most were classified as Grades 6-9 (60.9\%); the rest as Grades 10-16 (39.1\%)

TABLE 4

\section{FREQUENCY COUNTS FOR SELECTED VARIABLES ( $\mathbf{N}=92)$}

\begin{tabular}{|c|c|c|c|}
\hline Variable & Category & $n$ & $\%$ \\
\hline \multirow[t]{4}{*}{ Years with employer $^{\text {a }}$} & 2 to 4 years & 29 & 31.5 \\
\hline & 5 to 9 years & 34 & 37.0 \\
\hline & 10 to 19 years & 22 & 23.9 \\
\hline & 20 to 25 years & 7 & 7.7 \\
\hline \multirow[t]{4}{*}{ Years in automotive industry ${ }^{b}$} & 2 to 4 years & 16 & 17.4 \\
\hline & 5 to 9 years & 31 & 33.7 \\
\hline & 10 to 19 years & 24 & 26.1 \\
\hline & 20 to 34 years & 21 & 22.8 \\
\hline Full-time salaried employee & Yes & 92 & 100.0 \\
\hline \multirow[t]{2}{*}{ Highest education } & Bachelor's degree & 56 & 60.9 \\
\hline & Graduate degree & 36 & 39.1 \\
\hline \multirow[t]{2}{*}{ Position } & Grades 6-9 (individual contributor) & 56 & 60.9 \\
\hline & Grades 10-16 (management) & 36 & 39.1 \\
\hline
\end{tabular}

${ }^{\mathrm{a}}$ Years with employer: $M=8.53$ years, $S D=5.90 .{ }^{\mathrm{b}}$ Years in automotive industry: $M=11.91$ years, $S D=7.96$. 
Table 5 displays the psychometric characteristics for the ten summated scale scores for facilitators of career advancement and opportunities for promotion. The Cronbach alpha reliability coefficients ranged from $\alpha=.72$ to $\alpha=.94$, with a median alpha of $\alpha=.82$. Thus, the analysis indicated that all scales had adequate levels of internal reliability (Frankfort-Nachmais \& Nachmais, 2008)

\section{PSYCHOMETRIC CHARACTERISTICS FOR SUMMATED SCALE SCORES (N = 92)}

\begin{tabular}{lcccccc}
\hline & Number of & & & & \\
Score & items & $M$ & $S D$ & Low & High & $\alpha$ \\
\hline Facilitation from Informal Networks & 2 & 2.87 & 1.22 & 1.00 & 5.00 & .84 \\
Facilitation from Mentoring & 8 & 3.34 & 1.18 & 1.00 & 5.00 & .94 \\
Facilitation from Cultural Fit & 7 & 3.39 & 0.75 & 1.57 & 4.86 & .74 \\
Problems Developing Relationships & 4 & 2.46 & 0.95 & 1.00 & 4.75 & .81 \\
Problems Managing Own Career & 4 & 2.92 & 0.86 & 1.00 & 5.00 & .72 \\
Problems Obtaining Developmental Assignments & 4 & 2.84 & 1.08 & 1.00 & 5.00 & .88 \\
Problem Difficulty Getting Developmental & & & & & & \\
Assignments & 7 & 3.38 & 1.12 & 1.00 & 5.00 & .93 \\
Problems with Organizational Career Management & & & & & & \\
Processes & 3 & 3.79 & 0.94 & 1.33 & 5.00 & .75 \\
Problems Obtaining Opportunities for Geographic & & & & & & \\
Mobility & 3 & 3.18 & 1.10 & 1.00 & 5.00 & .80 \\
Opportunities for Promotion & 8 & 1.49 & 0.50 & 1.00 & 2.75 & .83 \\
\hline
\end{tabular}

\section{General Research Question}

The general research question was: What is the relationship between the linear combination of diversity management and career planning to the advancement of women working in the androcentric system within the United States automotive industry? The related null hypothesis was $H_{0:}$ :

The linear combination of diversity management and career planning is not related to the level of the career advancement of women working in the androcentric system within the automotive industry. Table 6 displays the results of the multiple regression model that predicted opportunities for promotion based on all nine scale scores. The final model was statistically significant $(p=.001)$ and accounted for $29.0 \%$ of the variance in the opportunities for promotion scale score. Specifically, higher scores for opportunities for promotion were related to lower scores for problem difficulty getting developmental assignments $(\beta=-.41$, $p=.004)$ and problems managing one's own career $(\beta=-.24, p=.04)$. This provided support to reject the null hypothesis for the general research question.

TABLE 6

PREDICTION OF OPPORTUNITIES FOR PROMOTION BASED ON SCALE SCORES MULTIPLE REGRESSION (N = 92)

\begin{tabular}{llllll}
\hline Variable & $B$ & $S E$ & $\mathrm{~B}$ & $p$ & $\mathrm{VIF}$ \\
\hline Intercept & 2.20 & 0.32 & & .001 & \\
Facilitation from Informal Networks & 0.01 & 0.04 & .01 & .90 & 1.28 \\
Facilitation from Mentoring & 0.01 & 0.05 & .02 & .90 & 1.77 \\
Facilitation from Cultural Fit & 0.08 & 0.08 & .12 & .30 & 1.50 \\
Problems Developing Relationships & -0.04 & 0.07 & -.08 & .55 & 1.89 \\
\hline
\end{tabular}




\begin{tabular}{llllll}
\hline Problems Managing Own Career & -0.14 & 0.07 & -.24 & .04 & 1.50 \\
Problems Obtaining Developmental Assignments & 0.05 & 0.06 & .12 & .40 & 2.26 \\
Problem Difficulty Getting Developmental Assignments & -0.18 & 0.06 & -.41 & .004 & 2.26 \\
Problems with Organizational Career Management Processes & 0.02 & 0.06 & .04 & .71 & 1.55 \\
Problems Obtaining Opportunities for Geographic Mobility & -0.05 & 0.05 & -.10 & .38 & 1.54 \\
\hline
\end{tabular}

Note. Final model: $F(9,82)=3.73, p=.001 . R^{2}=.290$. Durbin-Watson $=1.80$.

\section{Specific Research Question 1}

Research Question 1 was: What is the relationship between informal networks and the career advancement of women in the automotive industry? The related null hypothesis was $H 1_{0 \text { : There is no }}$ relationship between informal networks and the career advancement of women in the automotive industry. Table 7 displays the Pearson and Spearman correlations for facilitation from informal networks with opportunities for promotion. The Spearman correlation was also included for additional statistical verification. The relationship was not significant for the Pearson correlation $(r=.05, p=.63)$ or the Spearman correlation $\left(r_{s}=.08, p=.44\right)$, providing no support to reject the null hypothesis for RQ1.

\section{Specific Research Question 2}

Research Question 2 was: What is the relationship between mentoring and the career advancement of women in the automotive industry? The related null hypothesis was $H 2_{0}$ : There is no relationship between mentoring and the career advancement of women in the automotive industry. Table 7 displays the Pearson and Spearman correlations for facilitation from mentoring with opportunities for promotion. The relationship was significant for the Pearson correlation, where higher scores for facilitation from mentoring were related to higher scores for opportunities for promotion $(r=.23, p=.03)$, but the relationship was not significant for the Spearman correlation $\left(r_{s}=.19, p=.07\right)$. This provided partial support to reject the null hypothesis for Research Question 2.

\section{Specific Research Question 3}

Research Question 3 was: What is the relationship between cultural fit and the career advancement of women in the automotive industry? The related null hypothesis was $H 3_{0}$ : There is no relationship between informal networks and the career advancement of women in the automotive industry. Table 7 displays the Pearson and Spearman correlations for facilitation from informal networks with opportunities for promotion. The relationship was not significant for the Pearson correlation $(r=.02, p=.84)$ or the Spearman correlation $\left(r_{s}=.02, p=.87\right)$, providing no support to reject the null hypothesis.

\section{Specific Research Question 4}

Research Question 4 was: What is the relationship between problems developing relationships and the career advancement of women in the automotive industry? The related null hypothesis was $H 4_{0}$ : There is no relationship between problems developing relationships and the career advancement of women in the automotive industry. Table 7 displays the Pearson and Spearman correlations for problems developing relationships with opportunities for promotion. The relationship was significant for the Pearson correlation $(r=-.23, p=.03)$ and for the Spearman correlation $\left(r_{s}=-.22, p=.04\right)$; specifically, higher scores for problems developing relationships were related to lower scores for opportunities for promotion, providing support to reject the null hypothesis for Research Question 4.

\section{Specific Research Question 5}

Research Question 5 was: What is the relationship between problems managing one's own career and the career advancement of women in the automotive industry? The related null hypothesis was $H 5_{0}$ : There is no relationship between problems managing one's own career and the career advancement of women in the automotive industry. Table 7 displays the Pearson and Spearman correlations for problems managing 
one's own career with opportunities for promotion. The relationship was significant for the Pearson correlation $(r=-.38, p=.001)$ and for the Spearman correlation $\left(r_{s}=-.35, p=.001\right)$; specifically, higher scores for problems managing one's own career were related to lower scores for opportunities for promotion, providing support to reject the null hypothesis for Research Question 5.

\section{Specific Research Question 6}

Research Question 6 was: What is the relationship between problems obtaining developmental assignments and the career advancement of women in the automotive industry? The related null hypothesis was $H 6_{0:}$ : There is no relationship between problems obtaining developmental assignments and the career advancement of women in the automotive industry. Table 7 displays the Pearson and Spearman correlations for problems obtaining developmental assignments with opportunities for promotion. The relationship was significant for the Pearson correlation $(r=-.28, p=.007)$ and for the Spearman correlation $\left(r_{s}=-.33, p=\right.$ $.001)$; specifically, higher scores for problems obtaining developmental assignments were related to lower scores for opportunities for promotion, providing support to reject the null hypothesis for Research Question 6.

\section{Specific Research Question 7}

Research Question 7 was: What is the relationship between problem getting developmental assignments and the career advancement of women in the automotive industry? The related null hypothesis was

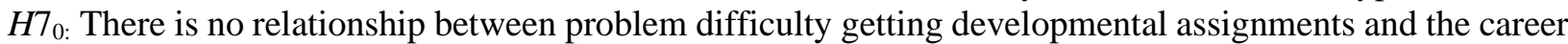
advancement of women in the automotive industry. Table 7 displays the Pearson and Spearman correlations for problems difficulty getting developmental assignments with opportunities for promotion. The relationship was significant for the Pearson correlation $(r=-.47, p=.001)$ and for the Spearman correlation $\left(r_{s}=-.52, p=.001\right)$; specifically, higher scores for problems difficulty getting developmental assignments were related to lower scores for opportunities for promotion, providing support to reject the null hypothesis for Research Question 7.

\section{Specific Research Question 8}

Research Question 8 was: What is the relationship between problems with organizational career management processes and the career advancement of women in the automotive industry? The related null hypothesis was $H 8_{0}$ : There is no relationship between problems with organizational career management processes and the career advancement of women in the automotive industry. Table 7 displays the Pearson and Spearman correlations for problems with organizational career management processes with opportunities for promotion. The relationship was significant for the Pearson correlation $(r=-.21, p=.05)$ and for the Spearman correlation $\left(r_{s}=-.26, p=.01\right)$; specifically, higher scores for problems with organizational career management processes were related to lower scores for opportunities for promotion, providing support to reject the null hypothesis for Research Question 8.

\section{Specific Research Question 9}

Research Question 9 was: What is the relationship between problems obtaining opportunities for geographic mobility and the career advancement of women in the automotive industry? The related null hypothesis was $H 9_{0}$ : There is no relationship between problems obtaining opportunities for geographic mobility and the career advancement of women in the automotive industry. Table 7 displays the Pearson and Spearman correlations for problems obtaining opportunities for geographic mobility with opportunities for promotion. The relationship was significant for the Pearson correlation $(r=-.22, p=.04)$ and for the Spearman correlation $\left(r_{s}=-.28, p=.007\right)$; specifically, higher scores for problems obtaining opportunities for geographic mobility were related to lower scores for opportunities for promotion, providing support to reject the null hypothesis for Research Question 9. 
TABLE 7

\section{PEARSON AND SPEARMAN CORRELATIONS FOR SCALE SCORES WITH OPPORTUNITIES FOR PROMOTION (N =92)}

\begin{tabular}{llll}
\hline & \multicolumn{3}{l}{ Opportunities for Promotion } \\
Variable & Pearson & Spearman \\
\hline Facilitation from Informal Networks & .05 & .08 \\
Facilitation from Mentoring & $.23 *$ & .19 \\
Facilitation from Cultural Fit & .02 & -.02 & \\
Problems Developing Relationships & $-.23 *$ & -.22 & $*$ \\
Problems Managing Own Career & $-.38 * * * *$ & -.35 & $* * * *$ \\
Problems Obtaining Developmental Assignments & $-.28 * * *$ & -.33 & $* * * *$ \\
Problem Difficulty Getting Developmental Assignments & $-.47 \quad * * * *$ & -.52 & $* * * *$ \\
Problems with Organizational Career Management Processes & $-.21 * *$ & -.26 & $* *$ \\
Problems Obtaining Opportunities for Geographic Mobility & $-.22 * *$ & -.28 & $* *$ \\
\hline
\end{tabular}
${ }^{*} p<.05 . * * p<.01 . * * * p<.005 . * * * * p<.001$.

\section{Additional Findings}

Table 8 displays the Pearson and Spearman correlations for four selected demographic variables with opportunities for promotion. Of the four variables, only length of time worked in the automotive industry had a significant relationship with opportunities for promotion. Specifically, more years worked in the automotive industry were related to lower scores for opportunities for promotion for the Pearson correlations $(r=-.24, p=.02)$ and Spearman correlations $\left(r_{s}=-.24, p=.02\right)$.

\section{TABLE 8}

\section{PEARSON AND SPEARMAN CORRELATIONS FOR SELECTED DEMOGRAPHICS WITH OPPORTUNITIES FOR PROMOTION ( $\mathbf{N}=92)$}

\begin{tabular}{|c|c|c|c|c|}
\hline \multirow[b]{2}{*}{ Variable } & \multicolumn{4}{|c|}{ Opportunities for Promotion } \\
\hline & Pearson & & Spearman & \\
\hline Years with employer & -.07 & & -.12 & \\
\hline Years in automotive industry & -.24 & $*$ & -.24 & $*$ \\
\hline Highest education & .11 & & .10 & \\
\hline Hierarchical position ${ }^{\mathrm{a}}$ & -.08 & & -.03 & \\
\hline \multicolumn{5}{|c|}{$\begin{array}{l}1=\text { Grades 6-9 (individual contributor), } 2=\text { Grades } 10-16 \text { (management) } \\
* p<.05 . * * p<.01 . * * * p<.005 . * * * p<.001 .\end{array}$} \\
\hline \multicolumn{5}{|c|}{$\begin{array}{l}\text { Table } 9 \text { displays the Pearson and Spearman correlations for selected variables with opportunities for } \\
\text { promotion. Twenty-one of } 42 \text { of the correlations were significantly related to opportunities for promotion. } \\
\text { For the sake of parsimony, the five largest correlations will be reported in the narrative. The opportunities } \\
\text { for promotion scale was negatively related to: (a) problems initiating moves across functions and businesses } \\
\text { for the Pearson }(r=-.41, p=.001) \text { and Spearman correlations }\left(r_{s}=-.44, p=.001\right) \text {; (b) problems being } \\
\text { offered key job assignments for the Pearson }(r=-.38, p=.001) \text { and Spearman correlations }\left(r_{s}=-.44, p=\right. \\
.001) \text {; (c) lack of opportunities to move across functions or businesses for the Pearson }(r=-.39, p=.001) \\
\text { and Spearman correlations }\left(r_{s}=-.46, p=.001\right) \text {; (d) not being considered when promotions for bigger jobs } \\
\text { arise for the Pearson }(r=-.49, p=.001) \text { and Spearman correlations }\left(r_{s}=-.54, p=.001\right) \text {; and (e) difficulty }\end{array}$} \\
\hline
\end{tabular}


getting access to opportunities for the Pearson $(r=-.53, p=.001)$ and Spearman correlations $\left(r_{s}=-.53, p=\right.$ .001) (see Table 9).

TABLE 9

\section{PEARSON AND SPEARMAN CORRELATIONS FOR SELECTED VARIABLES WITH OPPORTUNITIES FOR PROMOTION (N = 92)}

\begin{tabular}{|c|c|c|c|c|}
\hline \multirow[b]{2}{*}{ Variable } & \multicolumn{4}{|c|}{ Opportunities for Promotion } \\
\hline & Pearson & & Spearman & \\
\hline $\begin{array}{l}\text { Moral support and encouragement from your mentor or manager } \\
\text { during stressful times }\end{array}$ & .22 & $*$ & .21 & $*$ \\
\hline Having senior manager(s) who facilitate(s) your career progress & .23 & $*$ & .24 & $*$ \\
\hline Having role models & .24 & $*$ & .22 & $*$ \\
\hline Having a role model & .22 & $*$ & .22 & $*$ \\
\hline Developing relationships with senior managers & -.31 & $* * *$ & -.32 & $* * *$ \\
\hline Initiating own job changes & -.31 & $* * *$ & -.29 & $* *$ \\
\hline Initiating moves across functions and businesses & -.41 & $* * * *$ & -.44 & $* * * *$ \\
\hline Having a clear idea of your own career goals & -.24 & $*$ & -.20 & \\
\hline Being offered key job assignments & -.38 & $* * * *$ & -.44 & $* * * *$ \\
\hline Breadth of assignments or experiences & -.31 & $* * *$ & -.39 & $* * * *$ \\
\hline Not getting the right jobs early in your career (that you need for & & & & \\
\hline later advancement) & -.36 & $* * * *$ & -.40 & $* * * *$ \\
\hline Lack of opportunities to move across functions or businesses & -.39 & $* * * *$ & -.46 & $* * * *$ \\
\hline Difficulty getting access to critical developmental assignments & -32 & $* * *$ & -33 & $* * *$ \\
\hline Not being considered when promotions for bigger jobs arise & -.49 & $* * * *$ & -.54 & $* * * *$ \\
\hline Difficulty getting access to opportunities & -.53 & $* * * *$ & -.53 & $* * * *$ \\
\hline $\begin{array}{l}\text { Difficulty getting access to job assignments with bottom line } \\
\text { responsibility }\end{array}$ & -31 & *** & -34 & $* * *$ \\
\hline Not being offered stretch assignments & -.36 & $* * * *$ & -.40 & $* * * *$ \\
\hline Not knowing what the criteria are for advancement & -.14 & & -.22 & $*$ \\
\hline Being unsure about how to initiate a job change & -.25 & $*$ & -.27 & $*$ \\
\hline Needing to gain international experience in order to advance & -.21 & $*$ & -.19 & \\
\hline Not being considered for jobs that require relocation (domestic) & -.23 & $*$ & -.33 & $* * *$ \\
\hline
\end{tabular}
$* p<.05$. ** $p<.01$. *** $p<.005$. **** $p<.001$.

Table 10 displays the results of the stepwise regression model that predicted opportunities for promotion based on 55 candidate variables. Some interpretive caution is needed because some of these variables were ordinal ratings. The final three variable model was statistically significant $(p=.001)$ and accounted for $36.0 \%$ of the variance in opportunities for promotion. Specifically, opportunities for promotion were related to lower scores for difficulty getting access to opportunities $(\beta=-.49, p=.001)$, hierarchal position $(\beta=-.21, p=.04)$, and initiating moves across functions and businesses $(\beta=-.21, p=$ .03) (see Table 10). 


\section{TABLE 10 \\ PREDICTION OF OPPORTUNITIES FOR PROMOTION BASED ON SELECTED VARIABLES. STEPWISE REGRESSION $(\mathbf{N}=92)$}

\begin{tabular}{|c|c|c|c|c|c|}
\hline Variable & $B$ & $S E$ & $\beta$ & $p$ & VIF \\
\hline Intercept & 2.93 & 0.28 & & .001 & \\
\hline Difficulty getting access to opportunities & -0.18 & 0.04 & -.49 & .001 & 1.33 \\
\hline Hierarchal position ${ }^{a}$ & -0.21 & 0.09 & -.21 & .02 & 1.07 \\
\hline Initiating moves across functions and businesses & -0.09 & 0.04 & -.21 & .03 & 1.26 \\
\hline
\end{tabular}

Note. Final model: $F(3,88)=16.47, p=.001 . R^{2}=.360$. Durbin-Watson $=2.01$. Candidate variables $=55$.

${ }^{\text {a }} 1$ = Grades 6-9 (individual contributor), $2=$ Grades 10-16 (management)

\section{Summary}

In summary, this study used data from 92 female candidates for promotion into managerial and leadership positions in one United States-based automotive firm to investigate how diversity management and career planning are related to career advancement to improve the representation of women in management and senior-level positions. The general research hypothesis (DM and CP with opportunities for promotion) was supported (Table 6). Research Hypothesis 1 (informal networks and opportunities for promotion) was not supported (Table 7). Research Hypothesis 2 (mentoring and opportunities for promotion) was partially supported (Table 7). Research Hypothesis 3 (cultural fit and opportunities for promotion) was not supported (Table 7). Research Hypothesis 4 (problems developing relationships and opportunities for promotion) was supported (Table 7). Research Hypothesis 5 (problems managing own career and opportunities for promotion) was supported (Table 7). Research Hypothesis 6 (problems obtaining developmental assignments and opportunities for promotion) was supported (Table 7). Research Hypothesis 7 (problem difficulty getting developmental assignments and opportunities for promotion) was supported (Table 7). Research Hypothesis 8 (problems with organizational career management processes and opportunities for promotion) was supported (Table 7). Research Hypothesis 9 (problems obtaining opportunities for geographic mobility and opportunities for geographic mobility and opportunities for promotion) was supported (Table 7).

\section{Limitations of the Study}

Generalizability of the results was a principal limitation. One goal was to generalize the findings of this study to other U.S. automotive companies. However, due to the limited sample size, assumptions or inferences should not be made about other populations. Simon and Goes (2013) stated that a larger sample size enables a researcher to generalize to a larger population. The ideal sample size for this study was 108; however, the final sample size in this study was 92. Since the ideal number of participants was not achieve, Spearman's correlation in conjunction with Pearson's correlation were used to further determine the strength and the direction of the relationships between independent and dependent variables (Thirumalai, Chandhini, \& Vaishnavi, 2017).

A second limitation was the selection criteria to limit selection bias. Although the selection criteria remained unchanged, the change in the recruitment method may have introduced bias. The recruitment restrictions required the use of another method to recruit participants. Due to the organization's compliance regulations, solicitation for participation could only be sent to individuals who were known to the researcher. The survey link could not be sent using the corporate email. Interested participants received the survey invite via their personal email accounts. Ultimately, LinkedIn was used as another means to solicit participation. These guidelines may have introduced selection bias.

A third limitation was that the survey was initially limited to participants employed at a U.S. automotive manufacturer's sales company location. However, the need for more responses required the expansion of the sample population to female employees at the manufacturing facility. Employees employed at the manufacturing plant and satellite offices have access to fewer DM programs than the employees located at 
the corporate headquarters. Participants' responses may have varied based on the types of DM programs and $\mathrm{CP}$ initiatives at each geographic location and division.

\section{Implications}

This study provides awareness of the efficacy of DM and career planning as a solution to glass ceiling barriers. The findings contribute to the academic and scientific literature regarding the relationship between DM programs and CP initiatives for the advancement of women in the automotive industry.

The study contributes collective baseline quantitative data on the career advancement of women in the U.S. automotive industry. Positive social change may occur should HR leaders and diversity and inclusion practitioners choose to re-evaluate the efficacy of their existing initiatives using this study as the framework. Similarly, this study can be used as a blueprint for how companies could better offer their female individual contributors employed in entry-level positions equal access to resources and opportunities deemed to affect their career trajectory into managerial and leadership positions.

Women at various stages of their career may use these results of this study to re-evaluate their career advancement strategy. Additionally, participants reported two initiatives that have little impact on career advancement. Two null hypotheses were supported. Informal networking and cultural fit did not relate to career advancement. These results are contrary to previous research that states informal networking enhances social ties and provides access to resources such as access to information and decision-makers (Dennissen, Benschop, \& van den Brink, 2019). Women may be relieved to know that they can find a balance between how they spend their professional and personal time. Previous researchers suggested women feel compelled to choose informal work events over family time (Adams, Flynn, \& Wolfman, 2015; Clevenger \& Singh, 2013; Germain et al., 2012; O’Neil et al., 2011). However, based on the results of this study, women did not perceive there to be a significant link between informal networking and advancement.

Human Resource leaders may use this research to re-evaluate their talent development and succession planning strategies. Leaders may want to consider what programs women find valuable and dedicate their resources to creating or enhancing those programs and initiatives. Also, leaders may want to pay attention to how participants responded based on their age, experience, and tenure. This information may help inform which DM and CP programs may be most beneficial to organizations based on the demographic composition of their workforce. Moreover, HR professionals should consider the evidence that suggested that age has a significant role in women's perceptions about advancement. This information is pertinent when developing various platforms for professional development.

\section{CONCLUSION}

Women's increased participation in the labor forces has not led to more women into a managerial and senior-level position. In fact, women faced a more significant number of invisible and artificial barriers to career advancement than their male counterparts. Furthermore, the gender gap is more significant as women advanced into C-suite-level management positions (Devillard et al., 2014). However, women should continue to pursue efforts to improve representation in management and senior-level positions particularly in male-dominated industries such as the automobile industry.

The automotive industry is experiencing pressure to increase its gender diversity profiles and succession pipelines (Credit Suisse, 2012). This study may benefit companies seeking to develop programs and initiatives to shift an androcentric pipeline to one that reflects the gender diversity at the entry-level. The finding of this study may be used by HR professionals and organizational development professionals seeking to develop DM programs and CP initiatives to diversify the talent pipeline at all levels and better prepare women for career advancement. Future research should compare the efficacy of DM and CP for women working in U.S. automotive firms. Currently, General Motors Corp., Aston Martin of the Americas, and Lincoln Motor Company are the only automotive companies led by women. This study investigates the relationship between diversity management and career planning programs as solutions to gender related issues in the workplace. 
The results of this study concluded that women in the earlier stage of their career believe there was more opportunity for advancement. Chisholm-Burns, Spivey, Hagemann, and Josephson (2017) indicated that the opportunity for women to reach director-level or higher is brief. Researchers stated the women in senior management careers were more likely to enter management during the earlier part of their careers (McKinsey \& Company, 2019). Women need to seek advancement opportunities within a few years of taking an individual contributor position since promotional opportunities start to deteriorate the longer, they are in these roles. Women should consider voluntary job shifts, mobility resources, and non-traditional opportunity if they want to advance into management and leadership positions (O'Neil, Hopkins, \& Bilimoria, 2015; Spurk, Kauffeld, Barthauer, \& Heinemann, 2015). There are many possibilities that are open to women in a male-dominated industry. Getting the support from organizational leaders and supporting initiatives that will support other women in decision-making roles could fast-track women's positions and promote their careers.

Another recommendation is to examine individual factors affecting the career advancement of women in the automotive industry. There is limited research comparing how individual factors such as age and tenure affect women's career aspirations, successes, and challenges. Afande (2015) claimed that research on women's careers was generalized but did not consistently include age as a factor. Researchers should examine the difference, if any, age and tenure have in the career advancement of women. Differences and causal perceptions may vary by race, age groups, and industry (Afande, 2015).

Lastly, the findings of this study may contribute to social impact by providing young women practical insight into the benefits and efficacy of networking, sponsorships, global assignments, developmental opportunities, informal networks, and mentoring. Educational institutions could offer courses that teach women majoring in male-dominated professions how to navigate the workplace and advance into management. Organizations could create a policy that allows their employee's equal access to initiatives that will provide them the soft and hard skills needed to advance. Such programs could help close the gender gap in managerial and at the senior level.

\section{REFERENCES}

Adams, S.M., Flynn, P.M., \& Wolfman, T.G. (2015). Orchestrating the demise of all-male boards. Journal of Management Inquiry, 24, 208-211. doi:10.11177/1056492614546264

Afande, F.O. (2015). Factors affecting career development of women employees in the banking industry in Kenya. Research on Humanities and Social Sciences, 5(5), 1-36. doi:2224-5766

Alliance for Board Diversity. (2016). Missing pieces report: The 2016 board diversity census of women and minorities on Fortune 500 boards. Retrieved from http://theabd.org/2016\%20Board\%20Diversity\%20Census_Deloitte_ABD_Final.PDF

Appelbaum, S., Shapiro, B., Didus, K., Luongo, T., \& Paz, B. (2013). Upward mobility for women managers: Styles and perception: Part two. Industrial and Commercial Training, 45, 110-118. doi:10.1108/0197851311309552

Badal, S., \& Harter, J.K. (2014). Gender diversity, business-unit engagement, and performance. Journal of Leadership \& Organizational Studies, 21, 354-365. doi:10.1177/1548051813504460

Bartoll, X., Cortès, I., \& Artazcoz, L. (2014). Full-and part-time work: Gender and welfare-type differences in European working conditions, job satisfaction, health status, and psychosocial issues. Scandinavian Journal of Work, Environment \& Health, 40, 370-379. http://www.jstor.org/stable/43188031

Basar, P. (2015). The diversities of competitive advantage concepts and understanding sourced by resource-based approach to firm. International Journal of Business and Management, 10, 113125. doi:10.5539/ijbm.v10n5p113s

Beaman, L., Duflo, E., Pande, R., \& Topalova, P. (2012). Female leadership raises aspirations and educational attainment for girls: a policy experiment in India. Science (New York, N.Y.), 335(6068), 582-586. https://doi.org/10.1126/science.1212382 
Begeny, C.T., Ryan, M.K., Moss-Racusin, C.A., \& Ravetz, G. (2020). In some professions, women have become well represented, yet gender bias persists - Perpetuated by those who think it is not happening. Retrieved from https://advances.sciencemag.org/content/6/26/eaba7814

Brown, S.D., Lent, R.W., Telander, K., \& Tramayne, S. (2011). Social cognitive career theory, conscientiousness, and work performance: A meta-analytic path analysis. Journal of Vocational Behavior, 79, 81-90. doi:10.1016/j.jvb.2010.11.009

Budgeon, S. (2014). The dynamics of gender hegemony: Femininities, masculinities, and social change. Sociology, 48, 317-334. doi:10.1177/0038038513490358

Bukhari, S.S., \& Sharma, B.C. (2014). Workplace gender diversity and inclusive growth in public and private organizations. Indian Journal of Industrial Relations, 49, 551-564. Retrieved from http://journals.sagepub.com/home/jir

Bureau of Labor Statistics. (2018a). Table 11: Employed persons by detailed occupation, sex, race, and Hispanic or Latino ethnicity. Current Population Survey, Household Data Annual Averages. Retrieved from https://www.bls.gov/cps/cpsaat11.pdf

Bureau of Labor Statistics. (2018b). Women in the workforce: A databook (1077). Retrieved from https://www.bls.gov/opub/reports/womens-databook/2018/pdf/home.pdf

Catalyst. (2014). Quick take: Women in the automotive industry. Retrieved from http://www.catalyst.org/knowledge/women-automotive-industry\#footnote15_iufg0zz

Catalyst. (2015). Catalyst census: Women and men board directors. Retrieved from https://www.catalyst.org/knowledge/2015-catalyst-census-women-and-men-board-directors

Catalyst. (2017a). Quick take: Statistical overview of women in the workplace. Retrieved from http://www.catalyst.org/knowledge/statistical-overview-women-workplace

Catalyst. (2017b). Women in male-dominated industries and occupations. Retrieved from http://www.catalyst.org/knowledge/women-male-dominated-industries-and-occupations

Catalyst. (2018). Quick take: Women in the workforce: United States. Retrieved from http://www.catalyst.org/knowledge/statistical-overview-women-workforce

Chisholm-Burns, M.A., Spivey, C.A., Hagemann, T., \& Josephson, M.A. (2017). Women in leadership and the bewildering glass ceiling. American Journal of Health-System Pharmacy, 74(5), 312324. doi:10.2146/ajhp160930

Clevenger, L., \& Singh, N. (2013). Exploring barriers that lead to the glass ceiling effect for women in the U.S. hospitality industry. Journal of Human Resources in Hospitality and Tourism, 12, 376-399. doi:10.1080/15332845.2013.790258

Cook, A., \& Glass, C. (2014). Above the glass ceiling: When are women and racial/ethnic minorities promoted to CEO? Strategic Management Journal, 35, 1080-1089. doi:10.1002/smj.2161

Credit Suisse. (2012, August). Gender diversity and corporate performance. Research Institute. Retrieved from https://www.credit-suisse.com/newsletter/doc/gender_diversity

Curtis, E.A., Comiskey, C., \& Dempsey, O. (2016). Importance and use of correlational research. Nurse Researcher, 23, 20-25. doi:10.7748/nr.2016.e1382

Deloitte. (2015). Women at the wheel. Recruitment, retention, and advancement of women in the automotive industry. Retrieved from

https://www2.deloitte.com/content/dam/Deloitte/us/Documents/manufacturing/us-auto-100leading-women.pdf

Deloitte. (2015b). Women in manufacturing study: Exploring the gender gap. Retrieved from https://www2.deloitte.com/content/dam/Deloitte/us/Documents/Manufacturing/us-mfg-womenin-manufacturing-2015-study.pdf

Dennissen, M., Benschop, Y., \& van den Brink, M. (2019). Diversity networks: networking for Equality? British Journal of Management, 30(4), 966-980. doi:10.1111/1467-8551.12321

Devillard, S., Sanders-Sultan, S., \& Warner, C. (2014, April). Gender diversity in top management: Moving corporate culture, moving boundaries. Women Matter 2013. Retrieved from https://www.mckinsey.com/ /media/mckinsey/business\%20functions/organization/our\%20insigh 
ts/gender\%20diversity\%20in\%20top\%20management/gender\%20diversity\%20in\%20top\%20man agement.ashx

D'Netto, B., Shen, J., Chelliah, J., \& Monga, M. (2014). Human resource diversity management practices in the Australian manufacturing sector. International Journal of Human Resource Management, 25. doi:10.1080/09585192.2013.826714

Downes, M., Hemmasi, M., \& Eshghi, G. (2014). When a perceived glass ceiling impacts organizational commitment and turnover intent: The mediating role of distributive justice. Journal of Diversity Management, 9, 131-146. Retrieved from https://www.cluteinstitute.com/ojs/index.php/JDM/article/view/8971

Ellemers, N. (2014). Women at work: How organizational features impact career development. Policy Insights From the Behavioral and Brain Sciences, 1, 46-54. doi:10.1177/2372732214549327

Frankfort-Nachmias, C., \& Nachmias, D. (2008). Research methods in the social sciences (7th ed.). How to design and report experiments. New York, NY: Worth Publishers.

French, E., \& Strachan, G. (2013, July). Equal employment opportunity and its links to the participation of women in the construction industry: The case of Australia. Paper presented at the 6th Equality, Diversity and Inclusion International Conference: Social Solidarity, Equality, Diversity and Inclusion. Athens, Greece. Retrieved from http://eprints.qut.edu.au/63116/5/63116.pdf

Fujimoto, Y., Härtel, C.E., \& Azmat, F. (2013). Towards a diversity justice management model: Integrating organizational justice and diversity management. Social Responsibility Journal, 9 , 148-166. doi:10.1108/17471111311307877

Garnero, A., Kampelmann, S., \& Rycx, F. (2014). The heterogeneous effects of workforce diversity on productivity, wages, and profits. Industrial Relations: A Journal of Economy and Society, 53, 430-477. doi:10.1111/irel.12064

Germain, M., Herzog, M.J.R., \& Hamilton, P.R. (2012). Women employed in male-dominated industries: Lessons learned from female aircraft pilots, pilots-in-training, and mixed-gender flight instructors. Human Resource Development International, 15, 435-453. doi:10.1080/13678868.2012.707528

Greenberg, J. (1987). A taxonomy of organizational justice theories. Academy of Management Review, 12, 9-22. Retrieved from http://irpublicpolicy.ir/wpcontent/uploads/2017/08/Greenberg_1987_A_taxonomy_of_org_justice_theories.pdf

Greenberg, J. (1990). Organizational justice: Yesterday, today, and tomorrow. Journal of Management, 16, 399-432. doi:10.1177/014920639001600208

Hancock, M.G., \& Hums, M.A. (2015). A "leaky pipeline:" Factors affecting the career development of senior-level administrators in NCAA Division I athletic departments. Sport Management Review, 19. doi:10.1016/j.smr.2015.04.004

Harris, C.M., Pattie, M.W., \& McMahan, G.C. (2015). Advancement along a career path: The influence of human capital and performance. Human Resource Management Journal, 25, 102-115. doi:10.1111/1748-8583.12047

Harvard Business Review. (2013). Women in the workplace: A research roundup. Harvard Business Review, 91, 84-89. Business Source Complete, EBSCOhost database.

Hoobler, J.M., Masterson, C.R., Nkomo, S.M., \& Michel, E.J. (2018). The business case for women leaders: Meta-analysis, research critique, and path forward. Journal of Management, 44(6), 24732499. doi:10.1177/0149206316628643

inFORUM. (2012, July). NEXT generation tale. Do you have it? Retrieved from https://www.inforummichigan.org/automotivenext

Kellerman, B., \& Rhode, D.L. (2017). Women at the top: The pipeline as pipe dream. About Campus, 21, 11-18. doi:10.1002/abc. 21275

Kim, D., \& Starks, L.T. (2016). Gender diversity on corporate boards: Do women contribute unique skills? American Economic Review, 106, 267-271. doi:10.1257/aer.p20161032

Koenig, A.M., Eagly, A.H., Mitchell, A.A., \& Ristikari, T. (2011). Are leader stereotypes masculine? A meta-analysis of three research paradigms. Psychological Bulletin, 137, 616-642. doi:10.1037/a0023557 
Kretschmer, H., \& Kretschmer, T. (2013). Gender bias and explanation models for the phenomenon of women's discriminations in research. Scientometrics, 97, 25-36. doi:10.1007/s11192-013-1023-7

Lyness, K.S., \& Thompson, D.E. (2000a). Perceived barriers to career advancement scales. Psychtests. http://dx.doi.org/10.1037/t08649-000

Lyness, K.S., \& Thompson, D.E. (2000b). Perceived facilitators to career advancement scales. Psychtests. http://dx.doi.org/10.1037/t08650-000

Martin, A. (2015). America's evolution of women and their roles in the intelligence community. Journal of Strategic Security, 8, 99-109. doi:10.5038/1944-0472.8.3S.1479

Martin, P., \& Barnard, A. (2013). The experience of women in male-dominated occupations: A constructivist grounded theory inquiry. SA Journal of Industrial Psychology, 39, 1-12. doi:10.4102/sajip.v39i2.1099

McKinsey \& Company. (2012). Making the breakthrough. Women matter 2012. Retrieved from https://www.mckinsey.com/ /media/McKinsey/Business\%20Functions/Organization/Our\%20Insi ghts/Women\%20matter/Women_matter_mar2012_english\%20(1).ashx

McKinsey \& Company. (2013). Gender diversity in top management: Moving corporate culture, moving boundaries. Retrieved from https://www.mckinsey.com/ /media/McKinsey/Featured\%20Insights/Women\%20matter/Address ing\%20unconscious\%20bias/WomenMatter\%202013\%20Report\%20(8).ashx

McKinsey \& Company. (2015, February). Why diversity matters. Retrieved from http://www.mckinsey.com/insights/organization/why_diversity_matters

McKinsey \& Company. (2016). Women matter 2016. Reinventing the workplace to unlock the potential of gender diversity. Retrieved from https://www.mckinsey.com/ /media/mckinsey/featured\%20insights/women\%20matter/reinventin $\mathrm{g} \% 20$ the $\% 20$ workplace\%20for\%20greater\%20gender\%20diversity/women-matter-2016reinventing-the-workplace-to-unlock-the-potential-of-gender-diversity.ashx

McKinsey \& Company. (2019). Women in the Workplace 2019: Five Years in the path to equality is clear. Retrieved from https://womenintheworkplace.com/

O’Neil, D.A., \& Hopkins, M.M. (2015). The impact of gendered organizational systems on women's career advancement. Frontiers in Psychology, 6, 1-4. doi:10.3389/fpsyg.2015.0095

O’Neil, D.A., Hopkins, M.M., \& Bilimoria, D. (2015). A framework for developing women leaders: Applications to executive coaching. The Journal of Applied Behavioral Science, 51(2), 253-276. doi:10.1177/0021886315575550

O’Neil, D.A., Hopkins, M.M., \& Sullivan, S.E. (2011). Do women's networks help advance women's careers? Career Development International, 16, 733-754. doi:10.1108/13620431111187317

Patrick, A., \& Kumar, V. (2012, April-June). Managing workplace diversity: Issues and challenges. Sage Open, pp. 1-15. DOI: 10.1177/2158244012444615

Pew Research Center. (2021). U.S. women near milestone in the college-educated labor force. Retrieved from https://www.pewresearch.org/fact-tank/2019/06/20/u-s-women-near-milestone-in-thecollege-educated-labor-force/

Powell, G.N., \& Butterfield, D.A. (2015). The glass ceiling: What have we learned 20 years on? Journal of Organizational Effectiveness: People and Performance, 2, 306-326. doi:10.1108/JOEPP-092015-0032

Prieto, L.C., Phipps, S.T., \& Osiri, J.K. (2009). Linking workplace diversity to organizational performance: A conceptual framework. Journal of Diversity Management, 4(4), 13-21.

Reiners, B. (2021). What is the glass ceiling and how do we break it? A guide to understanding the glass ceiling metaphor. Retrieved from https://builtin.com/diversity-inclusion/glass-ceiling

Reinert, R.M., Weigert, F., \& Winnefeld, C.H. (2016). Does female management influence firm's performance? Evidence from Luxembourg banks. Financial Markets and Portfolio Management, 30, 113-136. doi:10.1007/s11408-016-0266-8

Sabharwal, M. (2015). From glass ceiling to glass cliff: Women in senior executive service. Journal of Public Administration Research and Theory, 25, 399-426. doi:10.1093/jopart/mut030 
Shaw, J.D., Park, T.Y., \& Kim, E. (2013). A resource-based perspective on human capital losses, HRM investments, and organizational performance. Strategic Management Journal, 34, 572-589. doi:10.1002/smj.2025

Shore, L.M., Chung-Herrera, B.G., Dean, M.A., Ehrhart, K.H., Jung, D.I., Randel, A.E., \& Singh, G. (2009). Diversity in organizations: Where are we now and where are we going? Human Resources Management, 19, 117-133. doi:10.106/j.hrmr.2008.10.004

Simon, M.K. \& Goes, J. (Ed). (2013). Dissertation and scholarly research: Recipes for success. Seattle, WA, Dissertation Success, LLC. Retrieved from www.dissertationrecipes.com

Singal, M. (2014). The business case for diversity management in the hospitality industry. International Journal of Hospitality Management, 40, 10-19. doi:10.1016/j.ijhm.2014.02.009

Smith, A.E., \& Monaghan, K.R. (2013). Some ceilings have more cracks: Representative bureaucracy in federal regulatory agencies. The American Review of Public Administration, 43, 50-71. doi:10.1177/0275074011420997

Smith, P.C., Kendall, L., \& Hulin, C.L. (1969). The measurement of satisfaction in work and retirement: A strategy for the study of attitudes. Chicago: Rand McNally.

Somerville, K., Elliott, C., \& Gustafson, C. (2012). Increasing women's participation on corporate boards in the USA. Journal of Business and Economics, 5, 1338-1348. doi:10.15341/jbe(21557950)/08.052014/013

Spurk, D., Kauffeld, S., Barthauer, L., \& Heinemann, N.S. (2015). Fostering networking behavior, career planning and optimism, and subjective career success: An intervention study. Journal of Vocational Behavior, 87, 134-144. doi:10.1016/j.jvb.2014.12.007

Thirumalai, C., Chandhini, S.A., \& Vaishnavi, M. (2017, April). Analysing the concrete compressive strength using Pearson and Spearman. In 2017 International conference of Electronics, Communication and Aerospace Technology (ICECA) (Vol. 2, pp. 215-218). IEEE.

Toossi, M. (2015, December). Labor force projections to 2024: The labor force is growing, but slowly. Monthly Labor Review. Retrieved from https://www.bls.gov/opub/mlr/2015/article/labor-forceprojections-to-2024-1.htm

United States Department of Education. (2016, Fall). National Center for Education Statistics, Integrated Postsecondary Education Data System (IPEDS). Completions component. (This table was prepared August 2017.) Retrieved from https://nces.ed.gov/programs/digest/d17/tables/dt17_318.30.asp

Uprichard, E. (2013). Sampling: Bridging probability and non-probability designs. International Journal of Social Research Methodology, 16(1), 1-11. doi:10.1080/13645579.2011.633391

Walker, N.A., \& Bopp, T. (2011). The underrepresentation of women in the male-dominated sport workplace: Perspectives of female coaches. Journal of Workplace Rights, 15, 47-64. doi:10.2190/WR.15.1.d

Watkins, M.B., \& Smith, A.N. (2014). Importance of women's political skill in male-dominated organizations. Journal of Managerial Psychology, 29(2), 206-222. https://doi.org/10.1108/JMP06-2012-0106

Williams, C.L., Kilanski, K., \& Muller, C. (2014). Corporate diversity programs and gender inequality in the oil and gas industry. Work and Occupations, 4, 440-476. doi:101177/0730888414539172

Worrall, L. (2012). Organizational cultures: Obstacles to women in the UK construction industry. Journal of Psychological Issues in Organizational Culture, 2, 6-21. doi:10.1002/jpoc.20088

Worrall, L., Harris, K., Stewart, R., Thomas, A., \& McDermott, P. (2010). Barriers to women in the UK construction industry. Engineering, Construction, and Architectural Management, 17, 268-281. doi:10.1108/09699981011038060

Zawadzki, M.J., Danube, C.L., \& Shields, S.A. (2012). How to talk about gender inequality in the workplace: Using WAGES as an experiential learning tool to reduce reactance and promote selfefficacy. Sex Roles, 67, 605-616. doi:10.1007/s11199-012-0181-z 